\title{
THE ENVIRONMENTAL RADIATION ANALYSIS ON THE RESIDENTIAL AREA AROUND NUCLEAR POWER PLANTS
}

\author{
Dong Han Yoo \\ Ulsan National Institute of Science and \\ Technology(UNIST) \\ UNIST-gil 50 Eonyang-eup Ulju-gun Ulsan \\ Metropolitan City 689-798, Republic of Korea
}

\author{
Hee Reyoung Kim \\ Ulsan National Institute of Science and \\ Technology(UNIST) \\ UNIST-gil 50 Eonyang-eup Ulju-gun Ulsan \\ Metropolitan City 689-798, Republic of Korea
}

\begin{abstract}
The environmental radiation level and radioactivity were analyzed in the Ulsan which is close to Nuclear Power Plants (NPPs). Ulsan is a Metropolitan city with a population of about $1,100,000$ residents, where the density of NPPs is the highest in Korea. Environmental radiation monitoring in Ulsan has been performed since the radiation monitoring facility was opened in August 2012 and the radioactivity was measured and analyzed in the environmental samples for five months in Ulsan. The measurement of environmental radiation and radioactivity was carried out periodically for various samples including airborne dust, fallout, tap water, and precipitation. Also, sampled were the soil, rice, cabbage, and indicator plants such as Artemisia and pine needles. The basic data from the radioactivity analyses brought a fundamental data for assessing the internal exposure dose for the public due to the intake of the radio nuclides included in those samples. On the other hand, the gamma radiation in the environment was measured continuously by using an environmental radiation monitor of the ion chamber type. Actually, the measurement of gamma radiation is thought to provide the base-line data on environmental radiation/radioactivity for radiological emergencies and the real-time information compared with the background radiation. The measurement analyses showed that the radiation level of the Ulsan area is kept at a normal background level in spite of the operation of many nuclear power plants near it.
\end{abstract}

\section{INTRODUCTION}

The objective of this project is to prepare a systematic data set on environmental radiation/radioactivity distribution in our country, which can be used as a criteria for assessing public health. The data is important for preserving national safety and the environment in the event that a radiological emergency situation should occur. It is necessary to know how much and what kind of radioactive substances are present in our region. This requires laboratory analyses of the samples collected by special equipment. The measuring devices detect even the smallest amounts of radioactive substances and changes in the radiation situation.

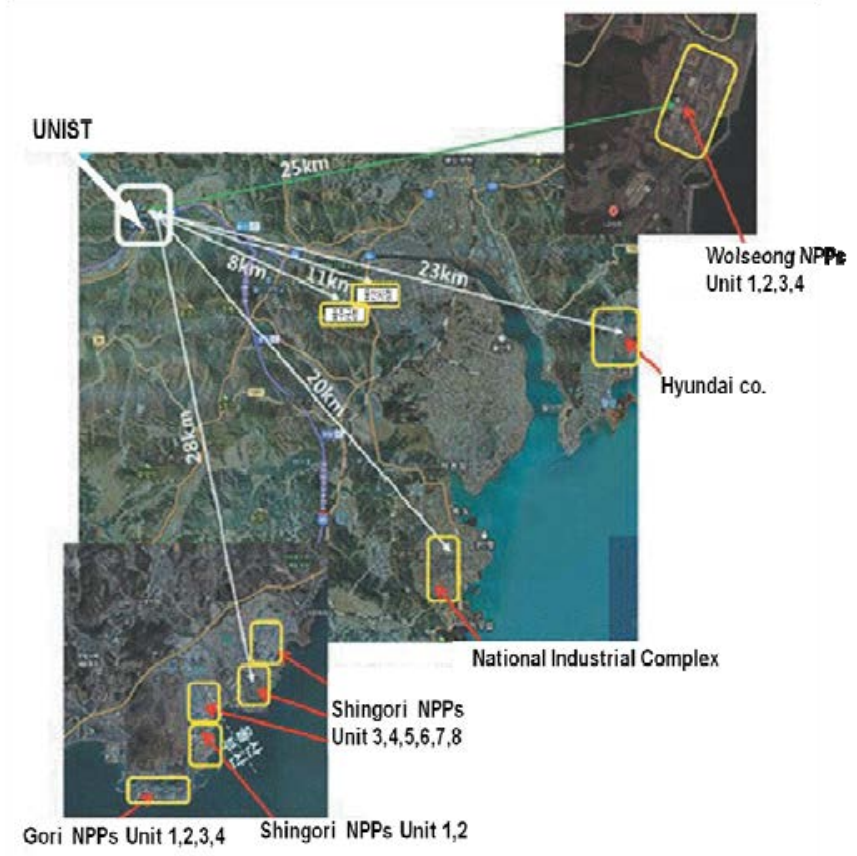

Figure 1. The distribution of Nuclear Power Plants around Ulsan 


\section{NOMENCLATURE}

At a regional monitoring station in Ulsan, gross beta activities in the airborne dust and, precipitation were measured from August 1st to December 31 2012.

We scanned for artificial radioactivity (Cs-137, etc) in particle-type airborne dust, gas-type airborne dust, tap water, fallout, and precipitation. We analyzed the samples to ascertain the effect of nuclear weapon tests or the operation of nuclear power plants.

As part of a nation-wide environmental radiation/radioactivity distribution survey for living environment, soil, rice, Chinese cabbage, and pine needles were sampled from somewhere around Ulsan and the North Gyeongnam regions, and have been secure basic foundations because radioactive substances absorbed into the human body.

After selecting the 5 most suitable places in the Gyeongnam Area, we surveyed ERM (Environmental Radiation Monitoring) biannually for checked fluctuation and radiation of the soil.

We sent TLDs to the central monitoring station in KINS quarterly.

Table 1. Environmental radiation / radioactivity monitoring program.

\begin{tabular}{|c|c|c|c|c|}
\hline Monitoring & \multicolumn{2}{|c|}{ Nuclide } & Period & Preprocessing \\
\hline \hline \multirow{2}{*}{ Airborne dust } & \multirow{2}{|c|}{ Gross-beta } & Weekly & $\begin{array}{c}\text { Low Volume Air } \\
\text { Sampler }\end{array}$ \\
\cline { 2 - 4 } & Gamma & Particle & Weekly & $\begin{array}{c}\text { High Volume Air } \\
\text { Sampler }\end{array}$ \\
\cline { 2 - 5 } & & Gas & Weekly & $\begin{array}{c}\text { Low Volume Air } \\
\text { Sampler }\end{array}$ \\
\hline \multirow{2}{*}{ Fallout } & Gamma & Monthly & $\begin{array}{c}\text { Evaporation } \\
\text { method }\end{array}$ \\
\hline \multirow{2}{*}{ Precipitation } & Gross-beta & rain & $\begin{array}{c}\text { Evaporation } \\
\text { method }\end{array}$ \\
\cline { 2 - 5 } & Gamma & Monthly & $\begin{array}{c}\text { Evaporation } \\
\text { method }\end{array}$ \\
\hline \multirow{2}{*}{ Tap water } & Gamma & Weekly & $\begin{array}{c}\text { Evaporation } \\
\text { method }\end{array}$ \\
\hline TLD & Sievert & Quarter & TLD \\
\hline
\end{tabular}
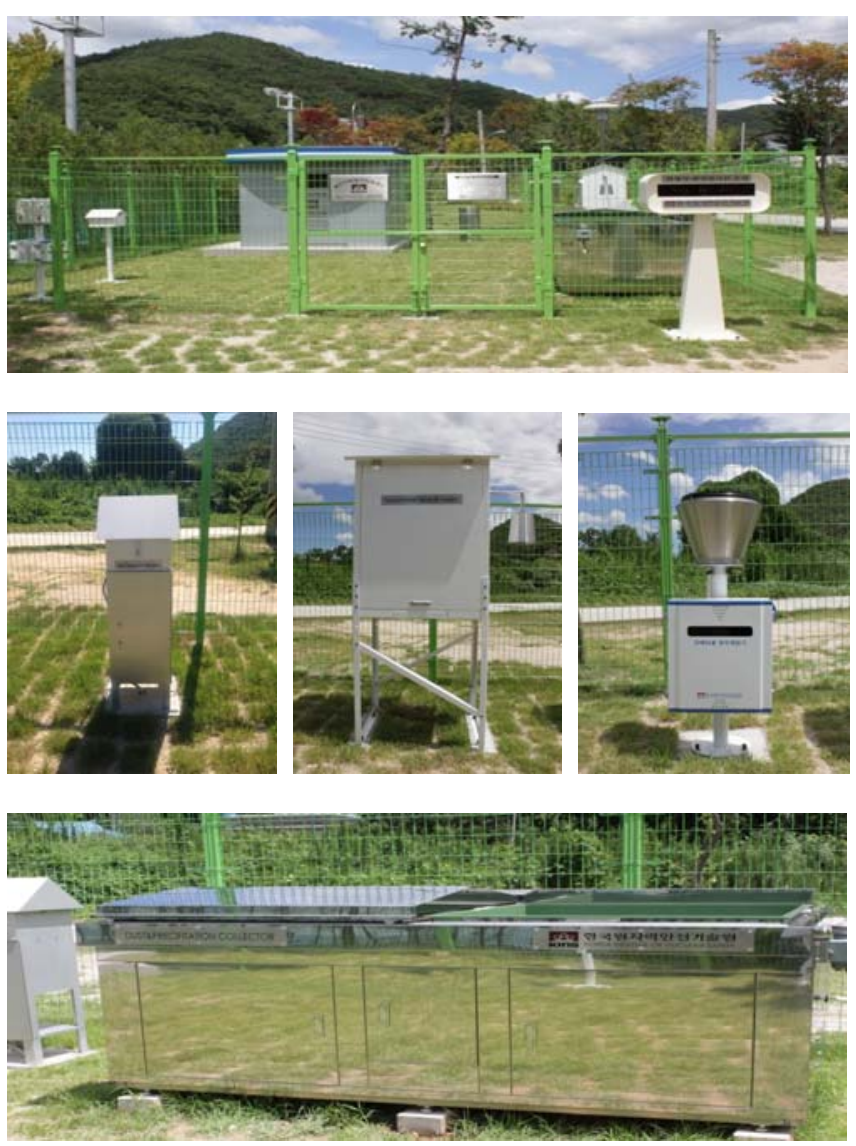

Figure 2. Monitoring Post

We collected precipitation, airborne-dust, fallout and tap water from the Monitoring Post.

- Airborne-dust: Collected by filter paper_(micro-fine borosilicate glass fiber filter paper, pore size $0.3 \mu \mathrm{m}$, collection efficiency of 99.9\%) located $1 \mathrm{~m}$ above the ground.

- Precipitation: When it was rained (or snowed), we collected over $100 \mathrm{~mL}$.

After collection they were detected through the preprocessing. Pretreatment is one of the important factors in the analysis process. We obtained multiple samples of airborne-dust, fallout, precipitation, tap water and soil from the post.

The obtained samples(dry and ashes) were deformed to fit the detector using a method such as concentration by evaporation. It must be very helpful to make accurate measurements.

We used 2-types of detector: a Low Background System for gross Beta, and a High-Purity Germanium Detector for gamma. These detectors must be calibrated before analysis. 

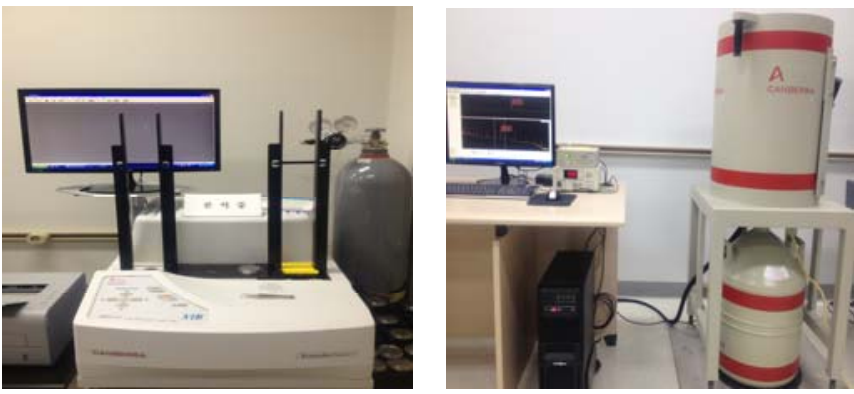

Figure 3. Low Background system and HPGe detector

The calibration method is shown as below

- Low Background System

$$
E f f=\frac{\left(n_{k}-n_{b}\right)}{N_{k}} \times 100
$$

\section{$N_{k}=$ Naturalabundance $\times$ Emit ratio $\times \lambda \times A$}

Where, Eff : The counting efficiency of the standard sample $\mathrm{nk}$ : gross counting rate of the standard sample (cpm) $\mathrm{nb}$ : background count rate (cpm)

$\mathrm{Nk}$ : Standard samples(Kcl) of radioactive (dpm)

Table 2. The instrument calibration results.

\begin{tabular}{|c|c|c|c|c|c|}
\hline \multirow{2}{*}{$\begin{array}{l}\text { Instrumentation and } \\
\text { operating conditions }\end{array}$} & \multicolumn{3}{|c|}{ Planchette } & \multicolumn{2}{|c|}{$\begin{array}{l}\text { Planchette } \\
\text { +Air Filter }\end{array}$} \\
\hline & $\begin{array}{l}\text { KCl } \\
(\mathrm{mg})\end{array}$ & $\begin{array}{c}\text { counting } \\
\text { time } \\
\text { (min.) }\end{array}$ & Eff.(\%) & KCl (mg) & Eff.(\%) \\
\hline \multirow{9}{*}{$\begin{array}{c}\text { Counting time } \\
\text { (Planchette+Filter) } \\
\text { : } 60 \text { min } \times 3 \text { time } \\
\text { period : Jul. 30th } \\
\text { Dec. 31st }\end{array}$} & 20.1 & 600 & $\begin{array}{r}54.1 \\
\pm 0.8\end{array}$ & $\begin{array}{r}0.99 \\
72\end{array}$ & $\begin{array}{l}52.7 \\
\pm 0.7\end{array}$ \\
\hline & 51.1 & 180 & $\begin{array}{r}47.7 \\
\pm 0.4\end{array}$ & $\begin{array}{r}1.49 \\
68\end{array}$ & $\begin{array}{l}52.9 \\
\pm 0.6\end{array}$ \\
\hline & 99.7 & 180 & $\begin{array}{r}48.6 \\
\pm 0.3\end{array}$ & $\begin{array}{r}1.98 \\
85\end{array}$ & $\begin{array}{l}51.6 \\
\pm 0.5\end{array}$ \\
\hline & 149.4 & 120 & $\begin{array}{r}50.6 \\
\pm 0.2\end{array}$ & $\begin{array}{c}\text { Average } \\
\text { efficiency }\end{array}$ & 52.4 \\
\hline & 199.7 & 60 & $\begin{array}{r}51.3 \\
\pm 0.2\end{array}$ & \multirow{5}{*}{\multicolumn{2}{|c|}{$\begin{array}{l}\text { Distilled water: } \\
\text { 20.1112g } \\
\text { KCl:1.544g } \\
\text { 63.065376dpm/g }\end{array}$}} \\
\hline & 401.8 & 60 & $\begin{array}{r}46.4 \\
\pm 0.1\end{array}$ & & \\
\hline & 599.8 & 60 & $\begin{array}{r}42.5 \\
\pm 0.1\end{array}$ & & \\
\hline & 801.5 & 60 & $\begin{array}{l}40.0 \\
\pm 0.1\end{array}$ & & \\
\hline & 1001.2 & 60 & $\begin{array}{r}39.5 \\
\pm 0.08\end{array}$ & & \\
\hline
\end{tabular}

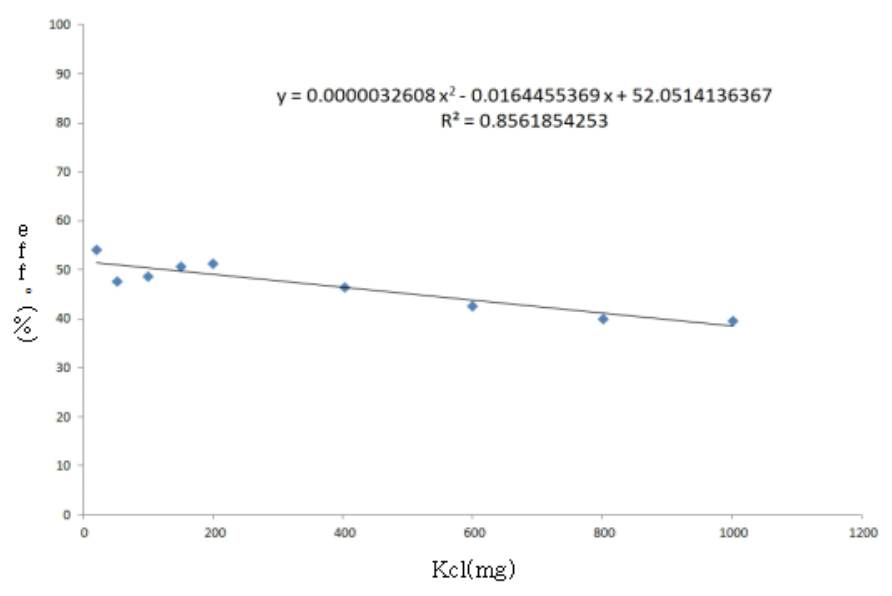

Figure 3. The efficiency curve of -Planchette (Kcl)

- HPGe detector

Table 3. Characteristics of HPGe detector.

\begin{tabular}{|l||l|c|}
\hline \multirow{2}{*}{\multicolumn{1}{|c||}{ Model No. }} & \multicolumn{2}{c|}{ GC3019-7500SL(CANBERRA Co.) } \\
\cline { 2 - 3 } & Relative Efficiency & $30 \%$ \\
\cline { 2 - 3 } \multirow{4}{*}{ Detector } & FWHM Resolution & $1.93 \mathrm{keV}$ at $1.33 \mathrm{MeV}$ \\
\cline { 2 - 3 } & Peak/Compton Ratio & 60.5 \\
\cline { 2 - 3 } & Diameter & $56.5 \mathrm{~mm}$ \\
\cline { 2 - 3 } & FWTM/FWHM & 1.85 \\
\hline \multirow{2}{*}{ Bias Voltage } & \multicolumn{2}{|c|}{$\sim 4000 \mathrm{~V}$} \\
\hline
\end{tabular}

Table 4. The information of Standard liquid. (U-8 bottle)

\begin{tabular}{|c|c|c|c|c|c|}
\hline Nuclide & $\begin{array}{c}\text { Energy } \\
(\mathrm{keV})\end{array}$ & $\begin{array}{c}\text { Ref. } \\
\text { Radioactivity } \\
(\gamma / \mathrm{s} / \mathrm{g})\end{array}$ & Dilution & $\begin{array}{c}\text { Dilution } \\
\text { of source } \\
\text { weight } \\
(\mathrm{g})\end{array}$ & $\begin{array}{c}\text { After dilution } \\
\text { Radioactivity } \\
(\gamma / \mathrm{s} \text { total })\end{array}$ \\
\hline \hline Am-241 & 59.54 & 4377 & & & 297.9279 \\
\hline Cd-109 & 88.03 & 5962 & & & 405.8136 \\
\hline Co-57 & 122.03 & 3130 & & & 213.0488 \\
\hline Ce-139 & 165.86 & 4412 & & 300.3103 \\
\hline Hg-203 & 279.2 & 10560 & & 718.7843 \\
\hline Sn-113 & 391.7 & 6180 & \multirow{5}{*}{0.2874} & \multirow{n}{*}{1.2443} & 420.6522 \\
\hline Sr-85 & 514.01 & 11980 & & 815.4390 \\
\hline Cs-137 & 661.66 & 4273 & & 290.8490 \\
\hline Y-88 & 898.04 & 14830 & & & 1009.4291 \\
\hline Co-60 & 1173.24 & 7507 & & & 510.9767 \\
\hline Co-60 & 1332.5 & 7507 & & & 510.9767 \\
\hline Y-88 & 1836.06 & 15710 & & & 1069.3278 \\
\hline
\end{tabular}




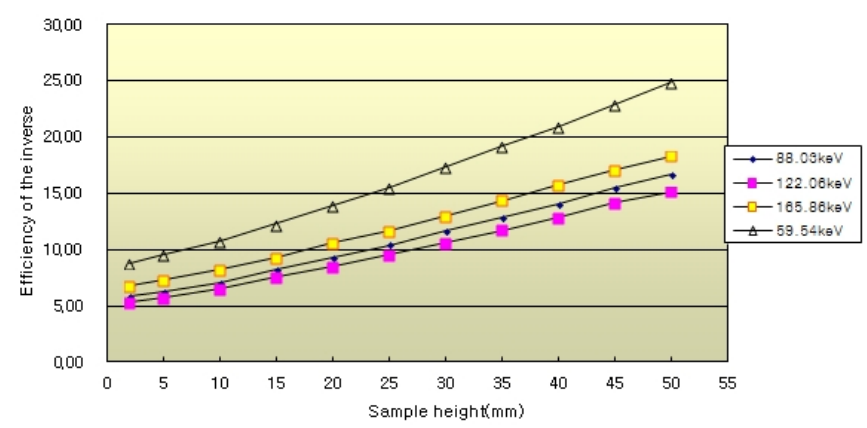

\section{RESULTS}

The counting range of gross beta activities after 48 hours was $1.45 \sim 13.9 \mathrm{mBq} / \mathrm{m}^{3}$ (The average annual gross-beta radioactivity for the airborne-dust was measured to be $5.935 \pm$ $\left.2.318 \mathrm{mBq} / \mathrm{m}^{3}\right)$, and the range of precipitation was $13.1 \sim 694$ $\mathrm{mBq} / \mathrm{L}$ (The average annual gross-beta radioactivity for the precipitation was measured to be $131 \pm 146 \mathrm{mBq} / \mathrm{L}$ )
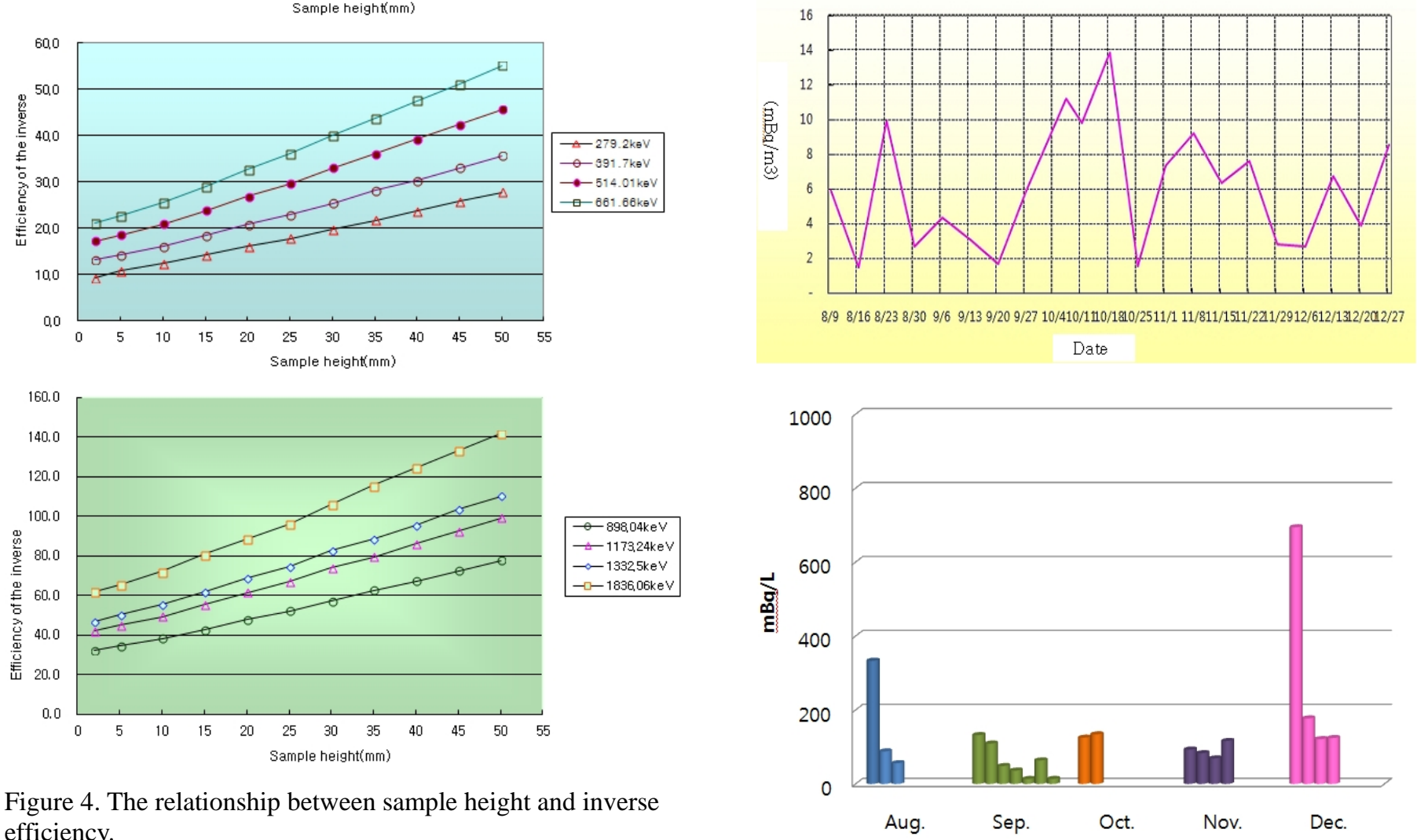

Figure 4. The relationship between sample height and inverse efficiency.

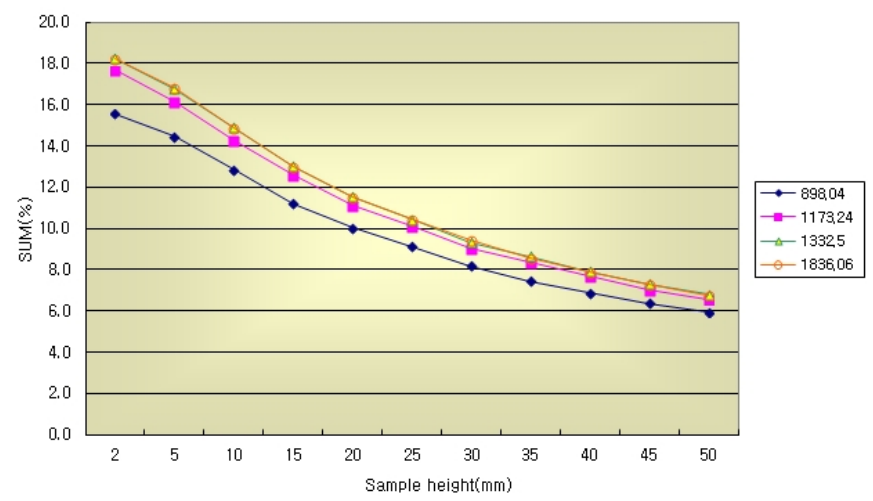

Figure 6. The graph of airborne-dust and precipitation

In the gamma analysis for the airborne-dust, the radioactivity concentrations of Be-7 were in the range of $1.5 \sim 3.48$ $\mathrm{mBq} / \mathrm{m} 3$. The radioactivity concentrations of $\mathrm{K}-40$ and Be-7 from the gamma analysis were measured to be in the range of $<0.479 \sim 1.18 \mathrm{~Bq} / \mathrm{m} 2 \cdot 30$ days and $4.22 \sim 23.1 \mathrm{~Bq} / \mathrm{m} 2 \cdot 30$ days for the fallout, $<1.590 \sim 2.29 \mathrm{mBq} / \mathrm{L}$ and $340 \sim 958 \mathrm{mBq} / \mathrm{L}$ for the precipitation.

Figure 5. The summing size of sample height. 

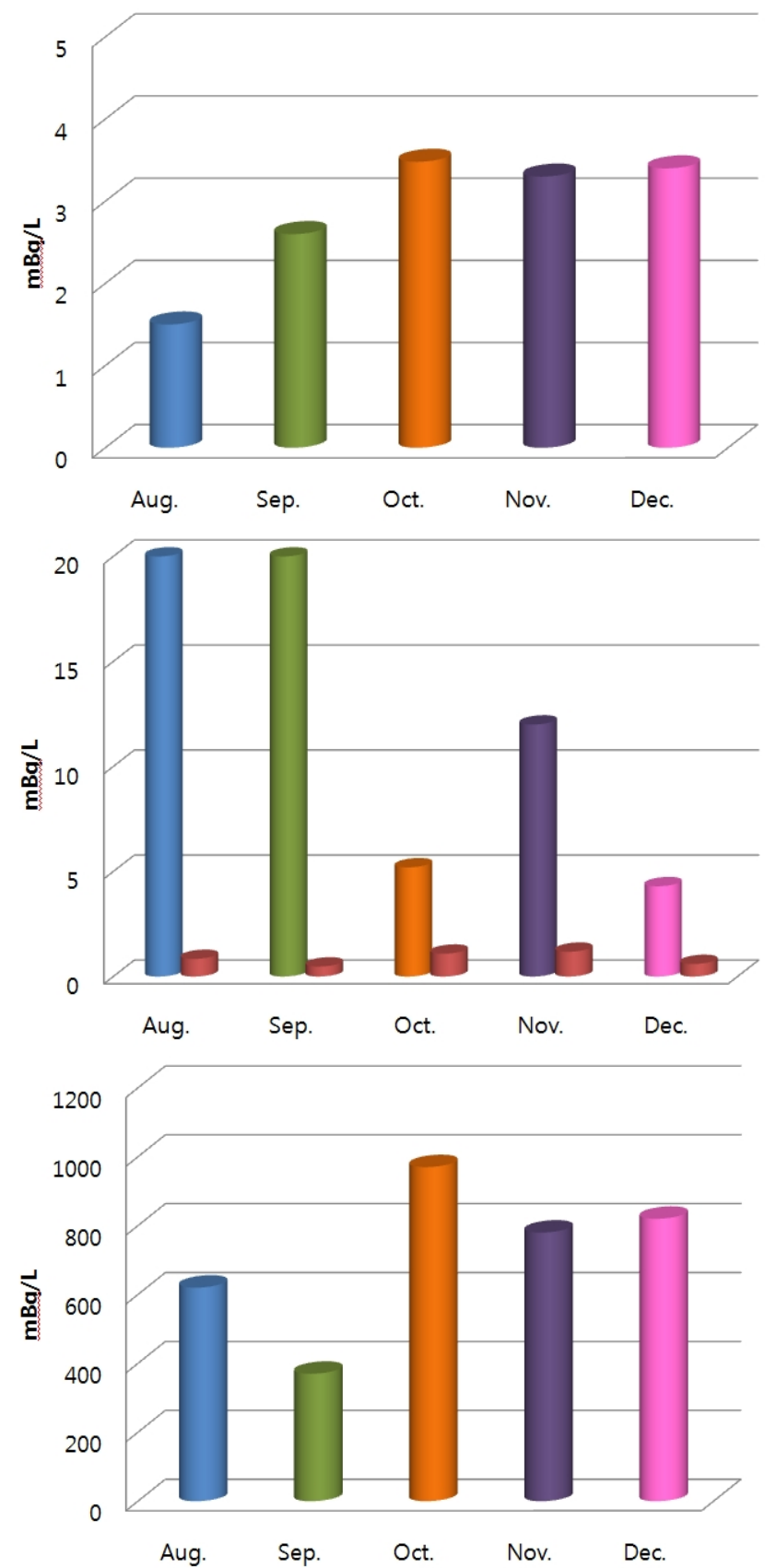

Figure 7. The graph of Be-7, K-40 from airborne-dust, precipitation, and fallout

The radioactivity concentrations of Cs-134, Cs-137 and I131 from the gamma analysis were not measured from the accident at the Fukushima nuclear power plant.

The gamma analysis for the soil, rice, chinese cabbage, and pine needles, to obtain the basic data of nation-wide environmental radioactivity, showed that there were no artificial radio nuclides except Cs-137 in some samples. The result of radioactivity analysis concentrations of Cs-137 were $11.4 \mathrm{~Bq} / \mathrm{kg}$.dry from pine needles on the surface of soil and 236 $\mathrm{Bq} / \mathrm{kg}$.dry from the pine needles.

\begin{tabular}{|c|c|c|c|}
\hline sample & $\begin{array}{c}{ }^{137} \mathrm{Cs} \\
(\mathrm{mBq} / \mathrm{kg} . \text { fresh })\end{array}$ & $\begin{array}{c}{ }^{7} \mathrm{Be} \\
(\mathrm{Bq} / \mathrm{kg} . \text { fresh })\end{array}$ & $\begin{array}{c}{ }^{40} \mathrm{~K} \\
(\mathrm{~Bq} / \mathrm{kg} . \text { fresh })\end{array}$ \\
\hline \hline $\begin{array}{c}\text { pine } \\
\text { needles }\end{array}$ & $236 \pm 20$ & $41.1 \pm 1.0$ & $136 \pm 3$ \\
\hline cabbage & $<51.5$ & $<0.369$ & $141 \pm 3$ \\
\hline rice & $<92.5$ & $<0.844$ & $23.2 \pm 0.8$ \\
\hline
\end{tabular}

As we mentioned above, the result of analysis of gross beta activities, gamma exposure rate, artificial radio-nuclide, lifeenvironment samplers for the airborne-dust, fallout, precipitation, and tap water, and gamma isotope of a standard menu which were measured in Ulsan Metropolitan City and North Gyeongnam regions between August and December in 2012 have not shown unusual radiological pollution marks.

\section{ACKNOWLEDGMENTS}

This work was supported by the Korea Institute of Nuclear Safety (KINS) \& the Nuclear Safety and Security Commission (NSSC)

\section{REFERENCES}

[1] Atoms, Radiation, and Radiation Protection (James E. Turner).

[2] Environmental Radiation Monitoring (KINS)

[3] The standard method of radionuclides (KINS)

[4] The standard environmental radioactivity survey procedures on the nuclear power plants (Kepco, 1999)

[5] Radiation Measurement (Ulsan University)

[6] Radiochemical ( Bae Young Il and Ryu Seuk Hwan 1993)

[7] Environmental Measurement Labortory in U.S.A. Department of Energy "HASl-300(EML procedures manual)" (1982)

[8] Radiation Detection and Measurement(Knoll)

[9] Environmental Radioactivity Monitoring in Daegu regions (Kyungpook National University, Vol 20, 2011)

[10] Environmental Radioactivity Survey Data in Korea (KINS, Vol 40, 2009)

[11] Environmental Radioactivity Survey Data in Korea (KINS, Vol 41, 2010)

[12] Environmental Radioactivity Survey Data in Korea (KINS, Vol 43, 2011) 